a patient with newly acquired right bundle-branch block? Though its appearance suggests the possibility of heart disease it is not specifically related to any condition. A simple history and examination should show up any apparent underlying cardiovascular disease needing treatment. Regular follow-up is justified; but in the absence of any other clinically evident cardiovascular abnormality patients should not have their activities restricted, nor should they need invasive investigation.

1 Wilson FN, McLeod AG, Barker PS. The order of ventricular excitation in human bundle-branch block. Am Heart f 1932; 7:305-30.

${ }^{2}$ Bayley RH. The frequency and significance of right bundle-branch block. Am f Med 1934;188:236-42.

${ }^{3}$ Reusch CS, Vivas JR. Clinical analysis of right bundle-branch block. Am Heart f 1959;58:543-6.

${ }^{4}$ Schneider JF, Thomas HE, Kreger BE, McNamarra PM, Sorlie P, Kannel WB. Newly acquired right bundle-branch block. The Framingham Study. Ann Intern Med 1980;92:37-44.

${ }^{5}$ Lasser RP, Haft JI, Friedberg CK. Relationship of right bundle-branch block and marked left axis deviation (with left parietal or peri-infarction block) to complete heart block and syncope. Circulation $1968 ; 37: 429-37$.

${ }^{6}$ Rotman M, Triebwasser JH. A clinical and follow-up study of right and left bundle-branch block. Circulation $1975 ; 51: 477-84$.

${ }^{7}$ Lancaster MC, Schechter E, Massing GK. Acquired complete right bundle-branch block without overt cardiac disease. Am f Cardiol 1972; 30:32-6.

\section{Drug information for patients: keep it simple}

What should patients be told about the drugs they take? How should they be told and who should tell them? Should they even be given any written information at all? And, if so, who should produce it and how should it be designed? These were some of the questions tackled by a recent meeting of the Medico-Pharmaceutical Forum.

The conference agreed that oral instructions from the doctor are not enough: doctors sometimes fail to give them, and patients often either do not understand or forget them. Many studies have shown the frightening results of incomprehension and forgetfulness; and instructions on the bottle, which seem simple and uncomplicated to the doctor and pharmacist, are often either wrong or misunderstood as well. These failings seem to make a case for clear written instructions to be given with the drug, but problems remain.

Carefully designed written information can improve compliance with drug taking, the conference was told, but studies of some leaflets have failed to show any improvement. The design of the leaflet is all important, and too many are overlong, overcomplex, and incomprehensible to many patients. The size of the leaflet, the language used, the typeface, layout, illustrations, and the explicitness and specificity of the content are all vitally important, and a deficiency in one aspect may render the leaflet useless. Yet the Medicines (Leaflets) Regulations of 1977 require pharmaceutical companies to include with their drugs either no information at all or a layman's version of everything that is given in the data sheets the doctor receives. This is patently absurd, and the conference thought that a good case could be made for repealing these regulations, although one drug company claimed that the Department of Health and Social Security would allow simpler instructions to be provided in addition to the layman's data sheet.

The problem of who is to produce such leaflets is difficult. Nobody seemed enthusiastic that it should be the drug companies alone, and anyway in Britain only about $20 \%$ of medicines are given to the patient as they come from the manufacturer: most are repackaged. The conference heard a proposal that some kind of national body should be established to produce these leaflets. This would mean uniformity and standardisation of the leaflets, and efficient use of resources; doctors, pharmacists, psychologists, consumers, and others could all be represented on such a national body-which could start by designing leaflets for six common drugs, and then do pilot studies to estimate their effectiveness. But will the Government tolerate another quango, who will pay, and who will distribute the leaflets? These issues were not much discussed. Nor was another phantom hanging over the conference: the proposed changes in product liability lawthe laws governing compensation for drug injury. The chairman asked that this issue-a complicated and controversial one-should be avoided, but new laws might require that extensive information should be given to patients on the drugs they take. Germany and Holland already require such information.

Undoubtedly we need well-designed leaflets giving clear information on drugs. We know something about designing such leaflets, but we have much to learn, and many doctors will be surprised by the simplicity and directness of the best leaflets. One well-known piece of equipment when it is bought new contains not only the usual complicated instructions but also a card saying: "We know nobody reads the instructions, but this is the one thing you must do, and these are the two things you must never do." This is perhaps the kind of leaflet we will need for drugs.

\section{Outcome of pregnancy after cone biopsy}

An inevitable consequence of cervical cytology screening is the problem of persistently positive smears in women who have not completed their families. Although a comprehensive screening programme does not change the rate of positive smears, it increases the number of young women who present for further investigation and treatment. ${ }^{1}$ The traditional investigation, cone biopsy, has the advantage that it provides adequate tissue on which the pathologist can base his diagnosis, and at the same time the biopsy will be sufficient treatment to deal with the lesion in many cases. ${ }^{2}$ On the other hand, cone biopsy is a mutilating procedure that may undermine the functional competence of the cervix during subsequent pregnancies.

Two studies ${ }^{3}{ }^{4}$ of the outcome of pregnancy after cone biopsy of the cervix found spontaneous abortion rates of $12 \%$ and $22 \%$ and premature labour rates of $7.5 \%$ and $9.5 \%$. Although these premature labour rates seemed high, firm conclusions could not be drawn because women who have had cone biopsies tend to be of higher maternal age and parity and of lower social class than the general population. In a recent study Jones et $a l^{5}$ compared the outcome of pregnancy in 66 mothers after cone biopsy with that in a carefully selected group of matched controls. They found that cone biopsy increased the premature delivery rate significantly from 5\% to $18 \%$ and the incidence of low-birthweight babies from $8 \%$ to $21 \%$. Although the difference fell short of formal significance, the caesarean section rate was also higher after cone 
biopsy; one mother required caesarean hysterectomy at 30 weeks after rupture of the uterus. These data reinforce the already strong case for treating young women with positive smears conservatively whenever possible, now a realistic goal thanks to the advent of colposcopy. ${ }^{6}$ We also have reassuring evidence that colposcopy in experienced hands is a reliable diagnostic tool, ${ }^{7}$ which can reduce the need for diagnostic cone biopsy by $90 \% \cdot{ }^{8}$ Under colposcopic control effective and less destructive localised treatment of the cervical lesion can be carried out by electrocoagulation, cryosurgery, or carbon dioxide laser. ${ }^{8}$

In Cardiff from 1965 to 1974, 372 of the 600 women who had a cone biopsy were potentially fertile, ${ }^{5}$ and the incidence of positive smears in young women is likely to increase. One of the most worrying statistics about invasive carcinoma of the cervix is that from 1970 to 1975 the death rate in England and Wales doubled in women under 34 years-at a time when mortality was falling in all other age groups. ${ }^{9}$ The rising death rate in younger women may well be due to changing sexual behaviour and, not surprisingly, there are calls for cytology to be offered to women of all ages. ${ }^{10-12}$ In the north east of England positive smears were found in 20 per 1000 women from 25 to 34 years and 5 per 1000 under 25 . The incidence of positive smears will depend on the population studied; in a group of girls who had been referred for termination under the age of 16 , for example, $7 \%$ needed cervical biopsy within 10 years of first referral. ${ }^{1}$ The anxiety created by a positive smear in a young woman does not provide a reason for immediate cone biopsy because $60 \%$ of the abnormalities found in women under 20 years will resolve without treatment. ${ }^{1}$ Investigation and treatment must be tailored to the individual case, and hence we should give priority to providing colposcopy services throughout the country.

Colposcopy will reduce but not eliminate the need for cone biopsy in women of child-bearing age and patients who conceive after an operation on the cervix should be assessed by the obstetrician as early as possible. The need for cervical suture will depend on the history and the clinical appearances of the cervix, and such a patient must have the closest supervision throughout pregnancy to ensure the maximum safety for both herself and the child.

${ }^{1}$ MacGregor JE, Teper S. Uterine cervical cytology and young women. Lancct 1978; ; :1029-31.

2 Green GH. The significance of cervical carcinoma in situ. Am $\mathcal{f}$ Obstet Gynecol 1966;94:1009-22.

${ }^{3}$ McCann SW, Mickal A, Crapanzano JT. Sharp conisation of the cervix. Observations of 501 consecutive patients. Obstet Gynecol 1969;33 470-5.

${ }^{4}$ McLaren HC, Jordan JA, Glover M, Attwood ME. Pregnancy after cone biopsy of the cervix. Fournal of Obstetrics and Gynaecology of the British Commonwealth 1974;81:383-4.

${ }^{5}$ Jones JM, Sweetnam P, Hibbard BM. The outcome of pregnancy after cone biopsy of the cervix: a case-control study. Br $\mathcal{F}$ Obstet Gynaecol $1979 ; 86: 913-6$.

${ }^{6}$ Coppleson M. Management of preclinical carcinoma. In: Jordan JA, Singer A, eds. The cervix. London: WB Saunders, 1976:453-72.

7 Kirkup W, Singer A, Hill AS. The accuracy of colposcopically directed biopsy in patients with suspected intraepithelial neoplasia of the cervix. Br F Obstet Gynaecol 1980;87:1-4.

${ }^{8}$ Singer S, Jordan JA. The management of premalignant cervical disease. In: Leeds DH, Singer $\mathrm{A}$, eds. Clinics in obstetrics and gynaecology. London: WB Saunders, $1978 \cdot \mathbf{5}: 629-57$.

${ }^{9}$ Yule R. Mortality from carcinoma of the cervix. Lancet 1978 ;i:1031-2.

${ }^{10}$ Miller AB. Mortality from carcinoma of the cervix. Lancet 1978;ii: 469-70.

${ }^{11}$ MacGregor JE, Teper S. Mortality from carcinoma of the cervix uteri in Britain. Lancet 1978;ii:774-6.

12 Andrews FJ, Linehan JJ, Melcher DH. Cervical cancer in younger women. Lancet $1978 ; \mathrm{ii}: 776-8$.
Too many doctors still regard acne as an untreatable affliction of adolescence-an attitude reflected in a recent survey that found that only one-third of all patients had ever had adequate treatment. ${ }^{1}$ Understanding the treatment of acne requires an appreciation of its pathogenesis, in which there are four major factors.

The most important factor is increased sebum production. The sebaceous glands are under complex endocrine control, ${ }^{2}$ being especially influenced by androgens from the testes and adrenals $^{3}$; and the severity of the patient's acne is related to the greasiness of his or her skin. ${ }^{4}$ The increased seborrhoea may be due to an increase of circulating androgens, especially of adrenal origin; but many patients show no such abnormality, ${ }^{5}$ which suggests that the abnormality is due to the overresponsiveness of the sebaceous glands. ${ }^{6}$

Secondly, the pilosebaceous ducts are obstructed. These are the ducts through which sebum passes to the surface of the skin. They are lined with keratin continuous with the adjacent epidermis. Some histological evidence suggests that an inflamed acne lesion is preceded by a non-inflamed lesion. ${ }^{7}$ Clinically, these non-inflamed lesions present as "whiteheads" or "blackheads"; but the underlying mechanism is uncertain. Certain fractions of the sebum may be comedogenic ${ }^{8}$ in experiments on animals but not in man.

The third factor is bacterial colonisation. The two main species of bacteria on skin prone to acne and in the follicular ducts are Staphylococcus epidermidis and Propionibacterium acnes. There is no simple relation between the numbers of these bacteria and the presence or severity of the acne, ${ }^{910}$ so what part do they play? Only a few follicles out of many thousands are affected at any one time. The growth of $P$ acnes and the production of biologically active substances by the bacteria vary in vitro with such physiological variables as oxygen tension and $\mathrm{pH} .{ }^{11}$ Since the microenvironment of the 